\title{
Of fat mice and men: the rise of the adipokines
}

\section{Simon J Dunmore}

Diabetes and Metabolic Disease Research Group, Department of Biomedical Science and Physiology, School of Applied Sciences, Research Institute in Healthcare Science, University of Wolverhampton, Wolverhampton WV1 1LY, UK
Correspondence

should be addressed to

S J Dunmore

Email

s.dunmore@wlv.ac.uk
The inexorable rise in obesity around the planet, particularly in developed countries but increasingly in the developing world, is accompanied by a parallel rise in co-morbid metabolic diseases including type 2 diabetes and vascular disease. Obesity, defined by an excess of adipose tissue, has complex aetiological factors that vary considerably between individual cases and across ethnic groupings but primarily involve genetic (and indeed epigenetic - see Drong et al. (2012)), environmental and behavioural contributions. New obesity genes are being identified regularly and range from those causing monogenic obesity such as mutations in the Lep gene to those that make a small but significant contribution to polygenic obesity such as the TCF7L2 and FTO genes. The cloning by Zhang et al. (1994), of the ob or Lep gene in mice, which produces a single-gene obesity, led to the identification of leptin, the first hormone-like product of adipose tissue to be identified and arguably one of the first 'adipokines' to be identified. This discovery underlined the increasingly apparent fact that adipose tissue is not merely an inert store of triacylglycerols but a highly metabolically active tissue with endocrine and other functions that allow it to influence many physiological processes ranging from appetite to metabolic control.

A wide range of secretory factors from adipose tissue have been (and are still being) subsequently found, some of which are known cytokines (e.g. TNF $\alpha$ (Hotamisligil et al. 1994)) and others of which were novel peptides or proteins such as adiponectin (Scherer et al. 1995). The term 'adipocytokine' was subsequently applied to these factors; however, the contracted term 'adipokine' is perhaps more appropriate as not all these products are also cytokines and many have wider hormonal properties (and indeed the term 'adipose-derived hormone', or similar, may be more appropriate for many adipokines but has yet to be adopted); in addition, some products such as visfatin (Brown et al. 2010) have enzymatic properties and some are not even proteins - for example free fatty acids released from adipocytes may also be seen in some circumstances as adipokines.

It is becoming increasingly apparent that adipokines form an important link between excessive adipose tissue (particularly in the visceral depots) in obesity and associated metabolic syndrome, type 2 diabetes and cardiovascular disease. The three thematic reviews in this issue of the Journal provide a timely survey of the evidence for adipokine involvement in these disorders - specifically, the contribution of adipokines to insulin resistance (Piya et al. 2012) and hence metabolic syndrome and type 2 diabetes, to $\beta$-cell failure (an essential element in the pathogenesis and progression of type 2 diabetes) (Dunmore \& Brown 2012) and to cardiovascular disease (Mattu \& Randeva 2012).

In their review, Piya et al. emphasise the inflammatory nature of obesity and related diseases and discuss the role of adipokines and cytokines in the inflammatory processes that lead to the development of insulin resistance. Adipose tissue is itself an important site of inflammation in obesity, which leads to dysregulation of adipokines, particularly in the visceral depots but also in a specific s.c. depot - that of the abdominal area, which of course overlies the visceral depot - with these areas secreting many pro-inflammatory adipokines. The authors discuss the contribution of elevated glucose and free fatty acids to adipokine inflammation and insulin resistance, underlining the centrality of the NF- $\kappa \mathrm{B}$ pathway to this process.

While insulin resistance is a key contributor to the pathogenesis of type 2 diabetes, it is rarely of itself sufficient to initiate the disease process as most obese individuals are insulin resistant but are able to increase insulin secretion and produce a hyperinsulinaemic response that maintains euglycaemia - type 2 diabetes

Published by Bioscientifica Ltd. 
develops when this capacity is impaired and $\beta$-cell failure develops. Dunmore \& Brown review the increasing evidence for a contribution of dysregulated adipokine levels to the process of $\beta$-cell failure in type 2 diabetes. The existence of an 'adipo-insular' axis is proposed and the many adipokine elements that form this axis are examined. The authors draw attention to the many intersecting intracellular pathways utilised by the different adipokines with varying effects on $\beta$-cell proliferation or apoptosis and on insulin synthesis and secretion. This clearly underlines the need for further studies of the effects of not just individual adipokines but of combinations as found in vivo in the different pathological states associated with obesity.

The review by Mattu \& Randeva emphasises the dichotomy between adipokines that are generally antiinflammatory and have beneficial effects (e.g. adiponectin and apelin) in cardiovascular disease and those that are mainly pro-inflammatory and deleterious (e.g. leptin and resistin). The effects of obesity, with the inevitable increase in adiposity, has varied consequences in terms of circulating levels of different adipokines - paradoxically some decrease, the most notable being adiponectin, whereas others increase and not always in the direction that might be expected (the 'beneficial' adipokine apelin increases for example!).

It is hoped that readers will find the three thematic reviews in this issue to be of interest and that many will be prompted to join the authors in endeavouring to understand the important contribution of adipokines to both health and to obesity-associated diseases. Finally, it is apparent from all these contributions that further research (in both 'mice' and 'men' - i.e. in animal models and in humans!) on the relative changes in blood concentrations of these hormonal and cytokine factors and into their combined effects in obesity, insulin resistance, type 2 diabetes and vascular disease will potentially lead to an improved knowledge of the pathophysiology involved and hence to better treatments for patients.

\section{References}

Brown JE, Onyango DJ, Ramanjaneya M, Conner AC, Patel ST, Dunmore SJ \& Randeva HS 2010 Visfatin regulates insulin secretion, insulin receptor signalling and mRNA expression of diabetes-related genes in mouse pancreatic beta-cells. Journal of Molecular Endocrinology 44 171-178. (doi:10.1677/JME-09-0071)

Drong AW, Lindgren CM \& McCarthy MI 2012 The genetic and epigenetic basis of type 2 diabetes and obesity. Clinical Pharmacology and Therapeutics 92 707-715. (doi:10.1038/clpt.2012.149)

Dunmore SJ \& Brown JEP 2013 The role of adipokines in $\beta$-cell failure of type 2 diabetes. Journal of Endocrinology 216 T37-T45. (doi:10.1530/ JOE-12-0278)

Hotamisligil GS, Arner P, Caro JF, Atkinson RL \& Spiegelman BM 1994 Increased adipose tissue expression of tumor necrosis factor- $\alpha$ in human obesity and insulin resistance. Journal of Clinical Investigations 95 2409-2415. (doi:10.1172/JCI117936)

Mattu HS \& Randeva HS 2013 Role of adipokines in cardiovascular disease. Journal of Endocrinology 216 T17-T36. (doi:10.1530/ JOE-12-0232)

Piya MK, McTernan PG \& Kumar S 2013 Adipokine inflammation and insulin resistance: the role of glucose, lipids and endotoxin. Journal of Endocrinology 216 T1-T15. (doi:10.1530/JOE-12-0498)

Scherer PE, Williams S, Fogliano M, Baldini G \& Lodish HF 1995 A novel serum protein similar to C1q, produced exclusively in adipocytes. Journal of Biological Chemistry 270 26746-26749. (doi:10.1074/jbc.270. 45.26746)

Zhang Y, Proenca R, Maffei M, Barone M, Leopold L \& Friedman JM 1994 Positional cloning of the mouse obese gene and its human homologue. Nature 372 425-432. (doi:10.1038/372425a0)

Received in final form 09 November 2012

Accepted 16 November 2012

Accepted Preprint published online 16 November 2012
C 2013 Society for Endocrinology Printed in Great Britain
Published by Bioscientifica Ltd. 